\title{
Projeto Ético-Político do Serviço Social e a construção de um Projeto Educacional Classista
}

\author{
Ethical-Political Project of Social Service and the construction of a Class Educational Project
}

\author{
JOANA VALENTE SANTANA (1) \\ BENEDITO DE JESUs PINHEIRO FERREIRA ${ }^{1}$ \\ ${ }^{1}$ Universidade Federal do Pará, Belém, PA, Brasil.
}

RESUMO - Este artigo, baseado em levantamento bibliográfico e documental, analisa a forma como a educação se insere no processo de luta de classes no contexto atual de degradação dos direitos sociais, resultante da efetivação de políticas neoliberais. Analisa as contradições entre distintos projetos de educação, ligadas ao processo de privatização dos serviços educacionais e descaracterização de seu sentido público e social. Contrariamente a essa tendência, discute-se uma concepção de educação capaz de articular-se a um projeto de superação do capitalismo, como condição para a emancipação humana. Aponta a atualidade do projeto ético-político do Serviço Social na construção de um projeto classista de educação que, ancorado na tradição marxista, valorize a formação profissional, a produção do conhecimento, o exercício profissional em articulação às lutas sociais em geral e em defesa da educação pública, laica, gratuita e de qualidade, referenciada em um projeto anticapitalista de sociedade.

Palavras-chave: Educação classista. Projeto ético-político do serviço social. Formação profissional. Emancipação humana.

ABSTRACT - This article, based on a bibliographical and documentary study, analyzes the way in which education is inserted in the process of class struggle in the current context of degradation of social rights, resulting from the implementation of neoliberal policies. It analyzes the contradictions between different education projects, related to the process of privatization of educational services and de-characterization of its public and social character. Contrary to this tendency, we discuss a conception of education capable of articulating with a project of overcoming capitalism as a condition for human emancipation. It points out the importance of the ethical-political project of the Social Service in the construction of a class-based education project that, anchored in the Marxist tradition, values professional qualification, knowledge production, and professional practice articulated to social struggles in general and in defense of public education, secular, free and of good quality, based on an anti-capitalist society project.

Keywords: Classist education. Ethical-political project of social service. Professional qualification. Human emancipation. 


\section{Introdução}

E ste artigo analisa, com base em levantamento bibliográfico e documental, a questão da educação inserida no processo de luta de classes, mediada pelos interesses das empresas capitalistas que ampliam seus lucros mediante à privatização dos serviços educacionais, associada ao avanço da degradação dos direitos sociais no mundo e na sociedade brasileira em especial, após décadas de políticas de orientação neoliberal. Contrariamente a essa tendência, o artigo discute uma concepção de educação capaz de articular-se a um projeto de superação do capitalismo, como condição para a efetiva emancipação humana. A partir dessas bases, discute um conjunto de elementos que devem nortear um projeto classista de formação para o profissional de Serviço Social, articulado às lutas de defesa da educação pública e das lutas anticapitalistas.

O fenômeno crescente da financeirização global, ligado a um endividamento insustentável dos estados talvez seja a face mais problemática da dinâmica de produção de crises de grandes proporções. Ao mesmo tempo em que frações de classe dominante continuam a produzir mais-valia ao redor do mundo, com base na superexploração do trabalho, a economia de trabalho vivo, como parte da busca de lucro, produz desemprego em escala mundial.

Nesse contexto, o Estado capitalista, com face ultraliberal, reatualiza seu papel de mantenedor dos interesses das frações de classe dominante ao retirar os direitos conquistados com as históricas lutas sociais. Para enfrentar as suas crises estruturais, o capital necessita criar incessantemente as condições de sua conservação, nas quais se inclui o enfraquecimento da organização política da classe trabalhadora, buscando minimizar as possibilidades do iminente tensionamento dos conflitos de classe, estratégia histórica da classe dominante. Segundo Coutinho (2011):

Parte daí a tendência do atual neoliberalismo no sentido de negar a sua natureza conservadora e de afirmar-se como "reformista" (ou mesmo, em muitos casos, como expressão de uma suposta "revolução liberal"). [...] Não é casual que o neoliberalismo apresente todas as suas propostas de desconstrução dos direitos sociais como "reformas", quando, na verdade, estamos diante de contrarreformas [...] (COUTINHO, 2011, p. 10).

Nesse contexto, a degradação dos direitos sociais, onde se inclui a educação pública, está articulada à fase atual do capital, de criação de estratégias de acumulação. As problematizações deste artigo, estão organizadas em três seções. A primeira discute o processo amplo de redução de direitos sociais, e especificamente como a educação vem sendo privatizada por grandes conglomerados ligados a fundos de investimentos, ao mesmo tempo em que o Estado minimiza o financiamento para essa área, e o reorienta parcialmente à lógica privatista. A segunda discute as contradições que se colocam no debate sobre fundamentos teóricos da educação, assumindo uma posição capaz de orientar a formação humana articulada à construção de uma sociedade emancipada. A terceira, argumenta os desafios da construção de um projeto classista de educação ancorados na reafirmação do Projeto Ético-Político do Serviço Social, mediante a discussão da formação profissional e das lutas no âmbito do acesso à educação pública e das lutas anticapitalistas.

\section{Reconfiguração do papel do Estado: esvaziamento dos direitos sociais e a especificidade da educação}

Em um contexto de crise do capital, as mais graves consequências recaem sobre a classe trabalhadora, em especial, nas suas frações mais pobres, e estas ocorrem mundialmente, porém de forma mais intensificada nos países da periferia do capitalismo, dada a sua histórica inserção subordinada na divisão internacional do trabalho. Mesmo após várias décadas de crise econômica, intensifica-se a formação de grandes fortunas. Cite-se a esse respeito o fato de que oito bilionários detêm a mesma riqueza que a metade mais pobre da população do planeta (OXFAM, 2017). 
No Brasil, o histórico e elevado grau de desigualdade ganha uma dimensão mais grave no quadro de destruição dos direitos consignados na Constituição Federal de 1988, tanto em termos dos deveres do Estado, no provimento de direitos básicos da cidadania, como na perda brutal de direitos trabalhistas, determinada em especial pela aprovação da contrarreforma trabalhista e da lei das terceirizações, que entraram em vigor em 2017. De outro lado, uma importante expressão da luta de classes traduz-se em um conjunto de políticas que têm como referência a disputa pelo fundo público: redução progressiva das despesas ligadas aos direitos sociais (saúde, educação, previdência etc.) com o consequente direcionamento crescente de recursos para pagamento de juros da dívida pública, e outros favorecimentos às classes hegemônicas, como a renúncia fiscal e as generosas renegociações de dívidas de grandes empresas.

Com a queda na taxa de lucro $^{1}$, a agressividade das classes hegemônicas nessa disputa aumenta. A degradação das políticas sociais é cotidianamente defendida pelos meios de comunicação de massa, em nome de um suposto equilíbrio das contas públicas, que não se observa na realidade econômica do país. Assim, a busca da "sustentabilidade fiscal" torna-se justificativa permanente para a retirada de direitos sociais, enquanto medidas que poderiam contribuir com a sua efetivação estão completamente ausentes da pauta política hegemônica, como a realização de uma reforma tributária que promovesse a taxação progressiva da renda ${ }^{2}$.

Uma das mais incisivas medidas nesse processo de disputa do fundo público foi a aprovação, em dezembro de 2016, da Emenda Constitucional no 95, que, ao instituir o "Novo Regime Fiscal", determina, por 20 anos, expressivos limites às despesas primárias (de onde se excluem pagamentos de juros, encargose amortizações da dívida) com consequências diretas nos gastos sociais, enquanto deixa completamente livres de limites os gastos financeiros. Cumpre destacar um aspecto nefasto dessa medida que, ao tornar a política de "austeridade" um dispositivo constitucional, praticamente impede que futuros governos revoguem ou revejam tal política, já que isto depende de ampla maioria parlamentar. Estudos recentes revelam os primeiros efeitos da emenda, com drásticas reduções em todas as áreas sociais. A análise da realização do orçamento 2017 aponta que nem sequer as previsões orçamentárias (já reduzidas em relação a 2016) foram cumpridas, com desvio de recursos para pagamento do serviço da dívida, medidas fiscais que "colocam em risco os direitos econômicos e sociais básicos de milhões de brasileiros, inclusive os direitos à alimentação, à saúde e à educação, ao mesmo tempo em que exacerbam as desigualdades de gênero, raça e econômica" (INESC/OXFAM/CESR, 2017, p. 1). Segundo esse estudo, importantes áreas dos direitos humanos, como o combate à pobreza extrema, à fome e à desnutrição, a violência contra a mulher e a desigualdade racial tiveram forte redução orçamentária. São reduções extremamente graves se forem considerados os déficits históricos bastante elevados em direitos humanos no Brasil.

Ao invés de buscarem um equilíbrio das contas públicas, trata-se de um avanço cada vez mais agressivo na apropriação do fundo público pelos setores hegemônicos: transferência de recursos vinculados aos direitos sociais para o lucro privado, em especial no setor financeiro; ampliação dos ganhos financeiros, com alta remuneração sobre os títulos da dívida pública etc. Cabe destacar que tais medidas rompem inclusive com normas internacionais que tratam dos limites que devem ter medidas fiscais de enfrentamento das crises econômicas, no que diz respeito a parâmetros mínimos de direitos humanos. Segundo essas normas, as medidas fiscais

devem ser temporárias, estritamente necessárias e proporcionais; não discriminatórias; levar em consideração todas as alternativas possíveis, inclusive medidas tributárias; proteger o conteúdo mínimo de direitos humanos; e ser adotadas após cuidadosa consideração e genuína participação dos grupos e indivíduos afetados nos processos de tomada de decisão (INESC/OXFAM/CESR, 2017, p. 1).

Longe de considerarem tais parâmetros, as atuais políticas liberais autofágicas apoiam-se em interesses de curto prazo, o que não pode deixar de constituir, como já alertava Gonçalves (2004, p. 135) há mais de uma década, um "processo marcado pela desestabilização macroeconômica, economias travadas, esgarçamento do tecido social, tensão permanente na política e degradação institucional". 
Além do esvaziamento de recursos, opera-se no senso comum (com decisiva participação dos veículos de comunicação de massa), a descaracterização de importantes direitos universais, e submissão dos serviços correlatos à lógica de mercado, com a ampliação de espaços para a realização de lucros na saúde, educação e previdência privada. Direitos são convertidos em mercadorias ou situados no campo da filantropia por parte de grandes empresas, que além de alcance social limitado, têm estado cada vez mais orientados para uma realização ainda maior de lucros ${ }^{3}$.

No campo educacional, esse processo de mercantilização apresenta uma nítida intensificação no Plano Nacional de Educação (PNE) 2014-2024 que, como afirma Lima (2015, p. 34): "indica o aprofundamento do privatismo e da certificação em larga escala como eixos condutores da política de educação brasileira". Já em 2002, se contabilizavam 320.354 matrículas nas redes públicas de ensino superior contra 1.090.854 nas instituições privadas (LIMA, 2015, p. 34). Nos últimos anos, além de um financiamento aquém das necessidades da sociedade brasileira, parte significativa de recursos do Ensino Superior foi direcionada ao setor privado, por conta de programas como o FIES e o Prouni, além de outras transferências, como bolsas de estudo. Trata-se de um embate histórico:

Os privatistas lutando pelo uso da verba pública para subsidiar o crescimento do setor privado, constituído pelas Instituições de Ensino Superior - IES com finalidade lucrativa e pelas IES sem finalidade lucrativa - comunitárias, filantrópicas, através das isenções e renúncias fiscais, e os militantes da educação pública reafirmando: verba pública exclusivamente para a educação pública! (LIMA, 2015, p. 32).

Se de um lado, o PNE 2014-2024 apresenta um balanço dessa disputa entre projetos para a educação, a favor da lógica privatista, cabe registrar que a efetivação de suas metas exigiria uma significativa elevação de recursos do setor. A meta 20 desse Plano estabelece que até o ano de 2024 as despesas com educação devem atingir $10 \%$ do Produto Interno Bruto, o que equivale quase a dobrar o atual volume de recursos financeiros (AMARAL, 2017). Daí se depreende a inviabilidade de tais metas no atual contexto de alta restrição fiscal imposta pela Emenda Constitucional (EC) 91.

Além da evidente frustração que isso representa com relação à possibilidade de resgate da histórica dívida educacional do país, só possível via setor público, cabe registrar a preocupante intensificação do processo de concentração de capital no setor privado, que vem se dando segundo interesses de grandes fundos de investimento ${ }^{4}$.

Esse conjunto de elementos, de precarização das condições de trabalho e esvaziamento de direitos fundamentais como dever do estado, caracteriza o patamar atual da luta de classes, que se manifesta também no campo educacional, tanto em termos de concepções pedagógicas, quanto no esvaziamento do caráter público da educação conforme será tratado na seção seguinte.

\section{Fundamentos para uma educação emancipadora e desafios postos pela luta de classes}

Considera-se, nesta seção, o processo educativo a partir de uma abordagem ontológica da formação humana (SAVIANI; DUARTE, 2012), isto é, tendo como suporte as categorias gerais definidoras do ser social, abstraindo-se, mas ao mesmo tempo incorporando, sua historicidade 5 . A consideração central aqui é a de que formação se identifica com humanização, em um duplo sentido: a formação sempre esteve entrelaçada ao processo genérico de humanização e é um elemento decisivo da humanização de cada indivíduo. Portanto, cumpre explicitar o que se entende por humanização. O ser humano, diferentemente dos outros animais, que se adaptam à natureza "tem de adaptar a natureza a si, isto é, transformá-la. E isto é feito pelo trabalho" (SAVIANI, 2005, p. 11). Seres humanos transformam a natureza no sentido da criação dos meios para a satisfação de suas necessidades, ao mesmo tempo produzindo novas necessidades, sendo este processo o "primeiro ato histórico" (MARX; ENGELS, 2007, p. 33).

Sendo assim, a teleologia cumpre um papel central no desenvolvimento humano: os indivíduos antecipam mentalmente a finalidade da sua ação. De outro lado, da inexistência de qualquer teleologia 
supra-humana, decorre que a essência humana não é dada pela natureza, muito menos por qualquer potência transcendental, mas é produzida coletivamente pelos próprios seres humanos na sua prática social e histórica. Ou seja, os seres humanos a partir da natureza constituem um mundo humano ou mundo da cultura.

Cada indivíduo, portanto, nasce pertencente à espécie humana, mas seu processo de humanização ainda é um devir. O efetivo pertencimento ao gênero humano será um contínuo processo de apropriação de um conjunto de conteúdos culturais desenvolvidos histórica e coletivamente; isto é, as objetivações relativas ao ser social.

De outro lado, se a humanização é esse processo de assimilação de elementos culturais fundamentais, a não assimilação (ou não apropriação) desses elementos é o seu contraponto, isto é, uma forma de alienação ${ }^{6}$, que assume uma dimensão histórica inédita no capitalismo, justamente pelo fato da sociedade humana ter desenvolvido notavelmente nos últimos séculos o seu poder, a sua capacidade criadora.

Com efeito, a humanidade, no capitalismo, foi capaz de revolucionar como em nenhum outro modo de produção anterior a sua potência produtiva. A competição entre capitalistas, necessidade imperiosa no sentido da sobrevivência nessa sociedade orientada pela obtenção da mais-valia, é uma das mais importantes determinações do desenvolvimento permanente das forças produtivas. O gênero humano desenvolveu a capacidade de produzir os meios para atender às suas (crescentes) necessidades com cada vez menor esforço. Ao lado das ciências, também a filosofia e as artes se desenvolveram de forma notável, ainda que de maneira fortemente marcada pela perspectiva da classe hegemônica. Em suma, dispomos hoje de riquíssimos elementos materiais e não materiais para a construção de uma sociedade igualitária e democrática; para alcançarmos o que Marx denominou de "reino da liberdade", em oposição ao "reino da necessidade" (MARX, 2010).

É importante destacar que se a dialética humanização/alienação se coloca no centro do processo educativo, este estará atravessado por antagonismos de classes, pois, na medida em que veicula os conhecimentos historicamente produzidos, opera a superação das concepções de mundo próprias do senso comum, bastante permeáveis à perspectiva da classe dominante. Senso assim, a educação constitui um importante instrumento de luta por uma relação hegemônica favorável à classe trabalhadora (SAVIANI, 2007).

Uma importante manifestação dessa disputa se dá no campo das teorias pedagógicas, que carregam perspectivas de classe ao se posicionarem sobre: determinada concepção de autonomia; a importância do conhecimento sistematizado; a relação professor-aluno e o papel de cada um no processo de aprendizagem; etc. Embora uma discussão ampla do tema esteja além dos limites deste estudo ${ }^{7}$, cabe citar, pela sua influência, o movimento que se deu marcadamente nas primeiras décadas do século XX, denominado Escola Nova, que se opõe frontalmente aos fundamentos da denominada "educação tradicional". Cabe reconhecer como pertinentes as críticas dirigidas à pedagogia tradicional, e em especial às práticas a ela associadas (SAVIANI, 2008), contendo elementos como o autoritarismo, a ênfase demasiada na memorização. Contudo, o movimento escolanovista não propõe, como é típico do desenvolvimento histórico, um processo de superação por incorporação, isto é, separando cuidadosamente os elementos válidos que deveriam ser acolhidos daqueles que deveriam ser rejeitados. Ao contrário, esse movimento rejeita de forma geral a escola tradicional e, sustenta a necessidade de diversos deslocamentos no processo educativo: "do aspecto lógico para o psicológico, dos conteúdos para os métodos, do professor para o aluno, do esforço para o interesse, da disciplina para a espontaneidade" (SAVIANI, 2013, p. 431). Secundariza-se, portanto, a importância da transmissão dos conhecimentos sistematizados e o papel do professor como um mediador entre o aluno e o acervo cultural humano.

Um aspecto desse deslocamento que exercerá grande impacto no debate educacional ao longo do século XX é a rejeição da necessidade do ensino (ou mesmo da aprendizagem) de conhecimentos sistematizados, dada a centralidade atribuída à aprendizagem (supostamente) autônoma do aluno. Para o escolanovismo, "o importante é aprender a aprender, isto é, aprender a estudar, a buscar novos conhecimentos, a lidar com situações novas" (SAVIANI, 2013, p. 431). Tal ideário exerce influência até os dias atuais em diversas propostas pedagógicas. Sob articulação dessa característica central (a secundarização da transmissão de 
conhecimentos), Duarte (2010) identifica um conjunto de concepções pedagógicas, por ele denominadas de "pedagogias do aprender a aprender", que hoje exercem forte hegemonia no campo pedagógico. Seus elementos principais são: a) ausência da perspectiva de superação da sociedade capitalista; b) negação da perspectiva de totalidade; c) relativismo epistemológico: dependência às condições particulares do sujeito cognoscente (com comprometimento da universalidade e da objetividade); e d) relativismo cultural: dependência do conhecimento aos significados atribuídos a eles em cada cultura (referência não à cultura humana, mas a uma miríade de culturas).

É nítida, portanto, a presença nessas concepções pedagógicas (em especial o construtivismo, a pedagogia do professor reflexivo, a pedagogia das competências, a pedagogia dos projetos e a pedagogia multiculturalista), de elementos da pós-modernidade e sua tendência à fragmentação (negação da totalidade) e rejeição da objetividade (EAGLETON, 1998). Essas concepções, portanto, levam a uma ausência de referência para a definição de conteúdos escolares a que todos os indivíduos precisem ter acesso. Ao contrário, prevalece a ideia de que "o cotidiano do aluno deve ser a referência central para as atividades escolares" (DUARTE, 2010, p. 37), esvaziando-se a perspectiva curricular.

Vale destacar ainda que os elementos típicos do escolanovismo se expressam nas concepções pedagógicas típicas da década de 1990 e primeiras décadas deste século com novas características: enquanto nas primeiras décadas do século XX, período de grande expectativa em relação aos impulsos industrializantes, o escolanovismo, segundo Saviani (2013), visava à integração dos indivíduos a uma sociedade "entendida como um organismo em que cada indivíduo tinha um lugar e cumpria um papel determinado em benefício de todo o corpo social" (SAVIANI, 2013, p. 432), no novo contexto histórico, de elevado desemprego, o aprender a aprender "liga-se à necessidade de constante atualização exigida pela necessidade de ampliar a esfera da empregabilidade" (SAVIANI, 2013, p. 432). Tal deslocamento de sentido - da aprendizagem como integração social à aprendizagem como elemento de luta em uma sociedade onde a competição é elevada ao paroxismo, - leva o autor a empregar a denominação "neoescolanovismo".

A atualização do escolanovismo, dada nesses termos, junta-se a outras tendências pedagógicas já bem conhecidas, como é o caso do construtivismo, onde a base piagetiana dos esquemas adaptativos elaborados pelos sujeitos em interação com o ambiente (equilibração e acomodação), é igualmente reconfigurada, resultando "despida do caráter cognitivo ligado à ideia de que o processo adaptativo, para ter êxito, suporia em algum grau o conhecimento do meio pelo sujeito, obtido por esquemas conceituais prévios" (SAVIANI, 2013, p. 437). No lugar do conhecimento verdadeiro, colocam-se as competências adaptativas.

Em suma, um conjunto de ideários pedagógicos são reconfigurados, dando centralidade ao objetivo de dotar os indivíduos de "empregabilidade", isto é, capacidade adaptativa a um ambiente de competição em uma sociedade crescentemente seletiva. A síntese dessas ideias se expressa no neoprodutivismo, "que surge em consequência das transformações materiais que marcaram a passagem do fordismo ao toyotismo, determinando uma orientação educativa que se expressa na 'pedagogia da exclusão'" (SAVIANI, 2013, p. 442).

Cabe notar que a hegemonia de tais tendências pedagógicas (tanto em termos do senso comum pedagógico quanto em termos de políticas oficiais) ajusta-se ao período de prevalência, no campo econômico, do neoliberalismo, e das orientações de políticas sociais dele decorrentes, isto é, de desmonte das políticas educacionais.

Nesse quadro de concepções conservadoras no campo da educação é necessária a reafirmação de seu princípio humanizador, capaz de

produzir, direta e intencionalmente, em cada indivíduo singular, a humanidade que é produzida histórica e coletivamente pelo conjunto dos homens. Assim, o objeto da educação diz respeito, de um lado, à identificação dos elementos culturais que precisam ser assimilados pelos indivíduos da espécie humana para que eles se tornem humanos e, de outro lado e concomitantemente, à descoberta das formas mais adequadas para atingir esse objetivo (SAVIANI, 2005, p. 13). 
Tal concepção afirma a importância da assimilação por todo indivíduo, dos conhecimentos científicos, filosóficos e artísticos em suas formas mais elaboradas, indispensáveis ao processo de humanização, posição que não se separa da necessária luta em defesa da educação pública e das políticas sociais em geral.

\title{
3 A construção de um projeto classista de educação ancorado na reafirmação do Projeto Ético-Político do Serviço Social: formação profissional e lutas políticas
}

O tema da educação voltada à emancipação humana assume relevância nas discussões em torno do Projeto Ético-Político do Serviço Social. O conjunto CFESS/CRESS no documento "Subsídios para a Atuação de Assistentes Sociais na Política de Educação" (201?) considera que

A educação é um complexo constitutivo da vida social, que tem uma função social importante na dinâmica da reprodução social, ou seja, nas formas de reprodução do ser social, e que [se dá] numa sociedade organizada a partir da contradição básica entre aqueles que produzem a riqueza social e aqueles que exploram os seus produtores e expropriam sua produção. Este complexo assume predominantemente o caráter de assegurar a reprodução dos contextos sociais, das formas de apreensão do real, do conjunto de habilidades técnicas, das formas de produção e de socialização do conhecimento científico que reponham contínua e ampliadamente as desigualdades entre as classes fundamentais e as condições necessárias à acumulação incessante. Integra, junto com outras dimensões da vida social, o conjunto de práticas sociais necessárias à continuidade de um modo de ser, às formas de sociabilidade que particularizam uma determinada sociedade. Sua função social, portanto, é marcada pelas contradições, pelos projetos e pelas lutas societárias e não se esgota nas instituições educacionais, embora tenha nelas um espaço privilegiado de objetivação (CFESS, [201?], p. 16).

A educação está inserida no processo das contradições do capital, mas ao mesmo tempo é um espaço de disputas pela emancipação humana.

\begin{abstract}
A educação, como dimensão da vida social, encerra as contradições que particularizam a vida social. Portanto, se a educação, sob o prisma do capital, se converte em um conjunto de práticas sociais que contribuem para a internalização dos consensos necessários à reprodução ampliada deste sistema metabólico, também e a partir dessa dinâmica é que se instauram as possibilidades de construção histórica de uma educação emancipadora, cujas condições dependem de um amplo processo de universalização do trabalho e da educação como atividade humana autorrealizadora. Trata-se, antes de tudo, de uma tarefa histórica, protagonizada por sujeitos políticos que compõem uma classe e precisam forjar processos de autoconsciência a partir da ação política, que produzam uma contra-hegemonia que atravesse todos os domínios da vida social, que impregne os modos de vida dos sujeitos singulares e sociais, as instituições educacionais e todas as demais também (CFESS, [201?], p. 18-19).
\end{abstract}

Desta forma, mesmo considerando as contradições no espaço da educação profissional, que é mediada pelos interesses da hegemonia burguesa, parte-se da premissa de que a educação pública, como uma das políticas sociais, é um espaço de lutas e de disputas em favor da classe trabalhadora. Isso porque a educação é uma das mediações do vínculo de homens e mulheres ao gênero humano, à construção da liberdade humana, lugar de apreensão crítica da existência da alienação, configurando-se como um campo de possibilidades do desenvolvimento das objetivações humanas. Um importante intelectual marxista do campo da educação no Brasil, Dermeval Saviani afirma que: 
Considerando-se que "toda relação de hegemonia é necessariamente uma relação pedagógica” (GRAMSCI, 1977a, p. 31), cabe entender a educação como um instrumento de luta. Luta para estabelecer uma nova relação hegemônica que permita constituir um novo bloco histórico sob a direção da classe fundamental dominada da sociedade capitalista - o proletariado. Mas o proletariado não pode erigir-se em força hegemônica sem a elevação do nível cultural das massas. Destaca-se aqui a importância fundamental da educação (SAVIANI, 2007, p. 3-4).

A formação profissional em Serviço Social (inicial e continuada) e a produção de conhecimento, portanto, devem ser considerados espaços privilegiados de disputa para a construção de um projeto classista de educação, que ao valorizar os processos educativos radicais de formação humana - com base na teoria social marxiana - possa oferecer insumos ao exercício profissional, às lutas pela democratização das políticas públicas, e às lutas anticapitalistas.

Está amplamente discutido que o Serviço Social brasileiro fez uma movimentação teórica e histórica de rompimento com o conservadorismo profissional, mediante a aproximação com a tradição marxista. A aproximação à teoria social de Marx teve importante rebatimento no Código de Ética Profissional (2012), na Lei de Regulamentação da Profissão (Lei no 8662/93) e nas Diretrizes Curriculares dos Cursos de Serviço Social, discutido pela ABEPSS (1996) e aprovado pelo MEC, sendo estas referências fundamentais para a construção do "Projeto Ético-Político do Serviço Social" que se posiciona contra todas as formas de exploração e opressão na ordem burguesa. Netto (2006), a esse respeito, afirma:

Na acumulação teórica operada pelo Serviço Social é notável o fato de, naquilo que ela teve e tem de maior relevância, incorporar matrizes teóricas e metodológicas compatíveis com a ruptura com o conservadorismo profissional - nela se empregaram abertamente vertentes críticas, destacadamente as inspiradas na tradição marxista. Isto significa que, também no plano da produção de conhecimentos, instaurou-se um pluralismo que permitiu a incidência, nos referenciais cognitivos dos assistentes sociais, de concepções teóricas e metodológicas sintonizadas com os projetos societários das massas trabalhadoras (ou seja: de concepções teóricas e metodológicas capazes de propiciar a crítica radical das relações econômicas e sociais vigentes). À quebra do quase monopólio do conservadorismo político na profissão seguiu-se a quebra do quase monopólio do seu conservadorismo teórico e metodológico (NETTO, 2006, p. 12-13).

Embora tenha havido inúmeros avanços no Serviço Social brasileiro, tem-se a permanência do conservadorismo profissional (NETTO, 2006) sendo reatualizado constantemente. Afirma Netto (2009) que o forte conservadorismo presente na profissão foi derrotado no Congresso da Virada, mas não foi suprimido da profissão. Assim, os rebatimentos inerentes à contrarreforma conservadora, elencados na primeira seção deste artigo, somam-se às velhas e novas disputas teóricas na formação e no exercício profissional . $^{8}$

Guerra (2010) afirma que, embora o Serviço Social brasileiro tenha avançado em valores relativos à emancipação humana (valor enunciado no Código de Ética da profissão), persiste uma leitura idealista desse projeto profissional baseada no senso comum, romantizada e moralizante. Tal leitura, "travejada pela visão religiosa do mundo, redunda em voluntarismo e messianismo que resiste a toda prova da realidade" (GUERRA, 2010, p. 46). No cotidiano profissional, dada a necessidade de respostas às situações concretas, muitas vezes os Assistentes Sociais acreditam que é possível prescindir dos elementos teórico-metodológicos e ético-políticos.

Desta forma, a formação profissional continua a ser um campo de disputa por projetos profissionais que se articulam a projetos societários de manutenção ou transformação da ordem burguesa. Muitas das posições que se apresentam como avançadas são efetivamente recomposições de posições conservadoras. É nesse sentido que a formação é um dos elementos importantes e seu caráter precisa ser objeto de cuidadosa reflexão.

O debate teórico no Serviço Social, ancorado na tradição marxista, historicamente posiciona-se contrariamente tanto ao pensamento conservador positivista como às teorias pós-modernas. Assim, dirige 
igualmente sua crítica ao persistente conservadorismo moral na formação profissional (em especial de viés religioso) e aos discursos pseudodemocráticos no interior da formação profissional que se identificam diretamente com a democracia formal-abstrata, e conduzem à ideia de que os assistentes sociais são capazes de "garantir direitos" mediante a defesa das políticas sociais, como se o Estado fosse um campo harmônico e sem conflitos, e onde o Assistente Social é capaz de dar resolutividade às expressões da questão social.

Somam-se às referidas disputas teóricas os elementos conjunturais de desmonte das universidades, que incidem na formação e produção de conhecimento em Serviço Social, tais como: a) a diminuição dos recursos federais para equipamentos de infraestrutura e para a pesquisa (em nível de graduação e pósgraduação); b) a alta carga de trabalho docente vinculada às exigências de produtividade acadêmica que, tem por consequência: a intensificação do adoecimento docente, a diminuição da valorização de espaços de discussão política nos sindicatos, o arrefecimento das atividades de assessoria aos movimentos sociais, via extensão universitária; e d) a expansão do ensino à distância, cuja formação é empobrecida e carente dos aportes teórico-metodológicos, ético-políticos e técnico-operativos profissionais, dentre outras.

Contrariamente a essas tendências, Guerra (2010) afirma que

[...] um projeto profissional crítico, no seu âmbito de realização, deve proporcionar os elementos para a crítica da sociabilidade burguesa e deter o potencial de apontar a direção, dar o norte de uma prática profissional crítica, autônoma e competente técnica, teórica e politicamente (GUERRA, 2010, p. 52, grifos do autor).

Assim reafirma-se o projeto ético político do Serviço Social brasileiro como norte e como parte da construção de um projeto classista de educação. Nessa construção, destacam-se três elementos: a formação profissional; a luta em defesa do ensino público, gratuito, laico e universal (democratização das políticas públicas) e as lutas anticapitalistas.

Em relação à formação profissional, considera-se que as diretrizes curriculares da $\mathrm{ABEPSS}^{9}$ contêm elementos para uma sólida formação profissional em Serviço Social e deve continuar a servir de orientação para um projeto de educação classista voltada à emancipação humana. Nessa direção, é pertinente a afirmação de Forti e Coelho (2015) de que

em face da importância - melhor dizendo, da necessidade - de nos colocarmos em prol de valores que confrontem a alienação, a desigualdade social e a banalização da vida, e, portanto, em prol do chamado projeto ético-político, parece-nos coerente envidarmos esforços para prosseguirmos no rumo que permitiu a sua construção e, assim sendo, não desconsiderarmos que é imprescindível a garantia de certo nível de conhecimentos teórico-práticos compatíveis com sua finalidade [...] (FORTI; COELHO, 2015, p. 27).

Desta forma, torna-se importante, no âmbito da formação profissional, a disputa no âmbito das distintas concepções e projetos pedagógicos. Tendo-se por base o método dialético marxiano, é primordial buscar as raízes das determinações da vida social na ordem burguesa (que põe a questão social e suas manifestações), e estabelecer, na particularidade do campo educacional, a apropriação da cultura historicamente construída como elemento de crítica e superação dessa ordem. A formação teórica de base marxiana permite a vinculação do projeto profissional a projetos societários para além do capital, que enfrentem criticamente (como anteriormente citado) o conservadorismo positivista, o irracionalismo pósmoderno e os discursos pseudodemocráticos ancorados na democracia formal abstrata. Concebendo-se o Estado como um campo de disputas de classe, devem ser consideradas as possibilidades de democratização das políticas públicas em favor dos trabalhadores, mas tendo-se clareza dos limites do Estado burguês.

Outro aspecto importante a se considerar é que o campo da formação profissional deve estar indissoluvelmente articulado à produção do conhecimento (em nível de graduação e pós-graduação), ao exercício profissional, e no caso particular da educação, às discussões das atribuições e competências dos/as assistentes sociais na Política de Educação ${ }^{10}$. Destaca-se, na formação graduada a importância do 
estágio supervisionado e dos Programas e Projetos de Extensão Universitária, como potenciais espaços de formação crítica dos discentes e de organização política junto aos movimentos sociais ${ }^{11}$, construindo-se uma intersecção com a educação popular ${ }^{12}$.

No que se refere à luta em defesa do ensino público, é fundamental a organização da categoria profissional em torno do conjunto CFESS/CRESS, da ABEPSS e da ampliação da participação dos docentes das Instituições do Ensino Superior no ANDES/SN ${ }^{13}$ e demais entidades ligadas à luta pela educação pública, gratuita, laica e de qualidade socialmente referenciada, que realizem análise crítica sobre a educação brasileira e a defesa dos recursos públicos para a educação.

Por último, a construção de um projeto classista de educação, ancorado no projeto ético político, deve, para além das lutas pela democratização das políticas públicas, continuar a se articular com as lutas anticapitalistas, considerando que esse projeto ético político não é somente crítico, é um projeto revolucionário, como afirma Guerra (2010). Daí que, dando centralidade e atuando nos espaços de contradição advindos da exploração de classe, deve continuar a se posicionar contra todas as formas de dominação/opressão existentes na sociedade.

A categoria profissional deve continuar, como afirmam Souza, Lovatto e Ramos (2012, p. 178), "na defesa da educação como a forma de socializar a todos e a cada um aquilo que a humanidade produziu e acumulou culturalmente ao longo de sua existência e que também deve servir a uma determinada classe social, a trabalhadora".

Em contraponto direto ao Programa Escola Sem Partido ${ }^{14}$, o Serviço Social, na defesa de uma educação pública classista, laica, gratuita e universal deve continuar a tomar partido e seguir na construção e fortalecimento da profissão que fez uma clara escolha, pela sociedade sem exploração de classes e contra qualquer forma de opressão.

\section{Considerações finais}

A crise atual do capital agrava sobremaneira a reprodução social da classe trabalhadora, submetida a uma lógica produtiva onde a busca incessante de lucros é o imperativo máximo e não o efetivo desenvolvimento humano. Tal lógica amplia a desigualdade econômica e social, expressa pela concentração de renda e crescimento da pobreza em nível mundial, com seus gravíssimos desdobramentos, especialmente nos países periféricos do capitalismo. A dificuldade de sustentação da taxa mínima de crescimento econômico diante do processo de financeirização da economia, o avanço do neoliberalismo que orienta as concepções e práticas governamentais de diminuição de direitos e desregulamentação trabalhista são expressões da crise do capital, que vem precarizando a vida da classe trabalhadora em momento de clara barbárie social ${ }^{15}$.

Nesse contexto, no Brasil, a educação é envolvida em um mecanismo de busca de lucros por grandes conglomerados capitalistas controlados por fundos de investimento, ao mesmo tempo que o Estado diminui fortemente o financiamento às políticas educacionais (educação básica e superior). Esse cenário é absolutamente preocupante visto que a educação é, contraditoriamente, um espaço de reprodução das relações sociais capitalistas e um campo de possibilidades para a aquisição de consciência acerca da realidade social e da necessidade de sua transformação. Porém, como garantir desenvolvimento humano se centenas de crianças, adolescentes e jovens fazem parte de famílias com baixíssima renda e têm acesso a espaços educacionais precarizados por infraestrutura física, baixos salários, adoecimento docente, escassos recursos para pesquisa e para a produção do conhecimento?

A realidade educacional no Brasil, demonstra que é necessário entender a educação no âmbito da luta de classes como forma de buscar elementos teórico-metodológicos que orientem a compreensão dos processos educacionais inseridos na realidade histórica, de modo a evidenciar as contradições postas nessa realidade em vista da construção de um projeto classista de educação em vista da emancipação humana.

Os intelectuais brasileiros que têm o aporte na teoria social de Marx (SAVIANI, 2005, DUARTE, 2013) defendem a tese de que os processos educativos são fundamentais para a apreensão do ser social em sua dimensão de totalidade. Nessa perspectiva, a formação educacional é um caminho para o processo 
de humanização do ser individual e genérico e como tal um caminho para valorização radical do gênero humano, o que deve confrontar-se com o processo de alienação humana, inerente ao processo de produção no capitalismo, onde segundo Marx, a humanidade perde-se de si mesma.

Nessa concepção de educação de base emancipatória, os componentes pedagógicos são fundamentais para a formação humana dos indivíduos mediante a incorporação dos conhecimentos produzidos pela humanidade (conhecimentos científicos, filosóficos e artísticos). A realidade educacional brasileira está muito distante dessa concepção de educação, motivo pelo qual tornam-se urgentes as diversas mediações de lutas para a construção de um projeto educacional que se volte à humanização.

Considerar um projeto classista de educação, é apreender a educação ela mesma inserida na luta de classes e ao mesmo tempo considerar os espaços educacionais como espaço de disputa da tomada de consciência de classe pelos trabalhadores em vista da construção de um projeto societário para a além do capitalismo.

Nessa medida, esse debate é importante para o Serviço Social brasileiro, considerando que o Projeto Ético-Político da categoria profissional se articula à defesa do ensino público, laico, gratuito e de qualidade, ao mesmo tempo em que esse projeto se articula às lutas anticapitalistas.

Nesse aspecto, considera-se a formação profissional (graduada e pós-graduada), mediada pela produção do conhecimento como um espaço de disputa teórico-metodológica, que orientada pela teoria social marxiana, possa incidir sobre o trabalho profissional de assistentes sociais e se articular às lutas democráticas de defesa de direitos (dentre eles a educação), mas, e fundamentalmente, à construção de um projeto anticapitalista na direção da emancipação humana.

\section{Referências}

ABEPSS/ASSOCIAÇÃO BRASILEIRA DE ENSINO E PESQUISA EM SERVIÇO SOCIAL. Diretrizes Gerais para o Curso de Serviço Social (Com base no Currículo Mínimo aprovado em Assembleia Geral Extraordinária de 8 de novembro de 1996). Rio de Janeiro, 1996.

ABREU, Marina Maciel. Serviço Social e a organização da cultura: perfis pedagógicos da prática profissional. São Paulo: Cortez, 2002.

AMARAL, NELSON C. Com a PEC 241/55 (EC 95) haverá prioridade para cumprir as metas do PNE (2014-2024)? Revista Brasileira de Educação, Rio de Janeiro, v. 22 n. 71, p. 1-25, out./dez, 2017. https://doi.org/10.1590/s141324782017227145

BANCO MUNDIAL. Um Ajuste Justo: Análise da eficiência e equidade do gasto público no Brasil. Brasil - Revisão das despesas públicas, v. 1: Síntese. Brasília: The World Bank Group, 2017.

BONFIM, Paula. Conservadorismo moral e Serviço Social. Rio de Janeiro: Lumen Juris, 2015.

CFESS/CRESS. Subsídios para a Atuação de Assistentes Sociais na Política de Educação. Gestão Tempo de Luta e Resistência. (2011-2014). Série 3. Trabalho e Projeto profissional nas políticas sociais. Brasília (DF), [201?].

CÓDIGO DE ÉTICA DO/A ASSISTENTE SOCIAL. Lei 8.662/93 de regulamentação da profissão. 10. ed. rev. e atual. [Brasília]: Conselho Federal de Serviço Social, 2012.

COUTINHO, Carlos Nelson. Prefácio. In: NETTO, Leila E. O conservadorismo Clássico: elementos de caracterização e crítica. São Paulo: Cortez, 2011.

DUARTE, Newton. O debate contemporâneo das teorias pedagógicas. In: MARTINS, Ligia; DUARTE, Newton (orgs.). Formação de professores - Limites contemporâneos e alternativas necessárias. São Paulo: Cultura acadêmica - UNESP, 2010. p. 33-49.

DUARTE, Newton. A individualidade para si. 3. ed. rev. Campinas: Autores associados, 2013.

EAGLETON, Terrry. As ilusões do pós-modernismo. Rio de Janeiro: Zahar, 1998. 
FORTI, Valéria; COELHO, Marilene. Contribuição à crítica do projeto ético-político do serviço social: considerações sobre fundamentos e cotidiano institucional. In: FORTI, Valéria; GUERRA, Yolanda (org.). Projeto Ético-Político do Serviço Social: contribuições à sua crítica. Rio de Janeiro: Lumen Juris, 2015. (Coletânea Nova de Serviço Social). p. 15-38.

G1. Desemprego sobe a 13,1\% em março e atinge 13,7 milhões de pessoas. 27.04.2018. Disponível em: https://g1.globo. com/economia/concursos-e-emprego/noticia/desemprego-fica-em-131-em-marco-e-atinge-137-milhoes-de-pessoas.ghtml. Acesso em: 05 maio 2018.

GONÇALVES, Reinaldo. Continuidade, antiliberalismo instrumental e ruptura: Lições da Argentina para o Brasil. Revista da Soc. Bras. Economia Política, Rio de Janeiro, n. 14, jun. p. 135-147, 2004.

GUERRA, Yolanda. Sobre a possibilidade histórica do projeto ético-político profissional: a apreciação crítica que se faz necessária. In: FORTI, Valéria; GUERRA Yolanda (org.). Projeto Ético-Político do Serviço Social: contribuições à sua crítica. Rio de Janeiro: Lumen Juris, 2010. (Coletânea Nova de Serviço Social).

HARVEY, David. O Enigma do Capital: e as crises do capitalismo. Tradução de João Alexandre Peschanski. São Paulo: Boitempo, 2011.

INESC/OXFAM/CESR. Brasil- Direitos humanos em tempos de austeridade. Estudo elaborado em parceria com a Oxfam Brasil e o Centro para Direitos Sociais e Econômicos. 2017.

LEHER, Roberto. Entrevista à Sessão Especial "A financeirização da economia e a privatização da educação". 38a Reunião Nacional da Associação Nacional de Pós-Graduação e Pesquisa em Educação - ANPED. out. 2017.

LIMA, Kátia. Plano Nacional de Educação 2014-2024: nova fase do privatismo e da certificação em larga escala. Universidade e sociedade, Brasília, n. 55, p. 32-43, fev. 2015.

LUKÁCS, György. Para uma ontologia do ser social I. São Paulo: Boitempo. 2012.

MARQUES, Rosa Maria; MENDES, Áquilas. A proteção social no capitalismo contemporâneo em crise. Revista Argumentum, Vitória (ES), v. 5, n.1, jan./jun. p. 135-163, 2013. https://doi.org/10.18315/argumentum.v5i1.5173

MARRO, Kátia I. Serviço Social e Movimentos Sociais: reflexões sobre experiências de extensão universitária. Temporalis, Brasilia, DF, ano 11, n. 22, p. 317-340, jul./dez. 2011.

MARX, Karl. Sobre a questão judaica. São Paulo: Boitempo, 2010.

MARX, Karl; ENGELS. F. A ideologia alemã. São Paulo: Boitempo. 2007.

NETTO, José Paulo. De como não ler Marx ou o Marx de Sousa Santos. In: NETTO, José Paulo. Marxismo impenitente: contribuição à história das ideias marxistas. São Paulo: Cortez, 2004. pp. 223-241.

NETTO, José Paulo. A Construção do Projeto Ético-Político do Serviço Social. In: Serviço Social e Saúde. Formação e trabalho profissional. São Paulo: Cortez, 2006.

NETTO, José Paulo. III CBAS. Algumas Referências para a sua Contextualização. In: CONSELHO FEDERAL DE SERVIÇO SOCIAL (org.). ABEPSS, ENESSO, CRESS/SP (Co-orgs.). 30 anos do Congresso da Virada, Brasília, 2009.

ONU/ORGANIZAÇÕES DAS NAÇÕES UNIDAS. OIT: desemprego e déficits de trabalho decente continuarão altos em 2018. 24.01.2018. Disponível em: https://nacoesunidas.org/oit-desemprego-e-deficits-de-trabalho-decente-continuarao-altosem-2018/. Acesso em: 5 maio 2018.

OXFAM BRASIL. A distância que nos une: um retrato da desigualdade brasileira. Relatório escrito por Rafael Georges e coordenado por Katia Maia. Setembro, 2017.

SANTOS, Josiane Soares. Neoconservadorismo pós-moderno e Serviço Social brasileiro. São Paulo: Cortez, 2007. (Coleção questões da nossa época).

SAVIANI, Dermeval. História das ideias pedagógicas no Brasil. Campinas: Autores Associados, 2013.

SAVIANI, Dermeval. Escola e Democracia. Campinas: Ed. comemorativa Autores Associados, 2008. 
SAVIANI, Dermeval. Pedagogia histórico crítica: primeiras aproximações. 9. ed. Campinas: Autores Associados, 2005. $160 \mathrm{p}$.

SAVIANI, Dermeval. Educação - do senso comum à consciência filosófica. 17. ed. Campinas, SP: Autores Associados, 2007. 293 p.

SAVIANI, Dermeval; DUARTE, Newton. A Formação humana na perspectiva histórico-ontológica. In: SAVIANI, Dermeval; DUARTE, Newton. Pedagogia histórico-crítica e luta de classes na educação escolar. Campinas/SP: Autores Associados, 2012. p. 13-35.

SILVEIRA JUNIOR. Adilson Aquino. A cultura pós-moderna no Serviço Social em tempos de crise. Temporalis, Brasília, DF, ano 16, n. 31, p. 167-187, jan./jun. 2016.

SOUZA Maristela da Silva, LOVATTO Guilherme Stürmer, RAMOS Fabrício Krusche. Resenha de LIMA, K. R. S. Reforma da educação superior nos anos de contra-revolução neoliberal: de Fernando Henrique Cardoso a Luis Inácio Lula da Silva. 2005. 469 f. Tese (Doutorado em Educação) - Faculdade de Educação, Universidade Federal Fluminense, Rio de Janeiro, 2005. In: Germinal: Marxismo e Educação em Debate, Salvador, v. 4, n. 1, p. 177-179, jun. 2012. p. 177-179.

\section{Notas}

${ }^{1}$ A garantia de um nível "aceitável" de lucratividade para a classe burguesa depende de uma taxa de crescimento regular mínima em torno de 3\% do PIB mundial (HARVEY, 2011). Por outro lado, as manifestações do débil desempenho econômico, assim como das reestruturações produtivas, atingem frontalmente a classe trabalhadora, como mostra o avanço brutal do desemprego e do trabalho vulnerável. Estudo da OIT, aponta em 2017 uma taxa global de 5,6\% de desemprego, o que atinge mais de 192 milhões de pessoas no mundo. E um agravante é o fato de que cerca de 1,4 bilhão de trabalhadores estavam em empregos precários no mesmo ano, com expectativa de acréscimo, a esse número, de 35 milhões até 2019. (ONU, 2018). No Brasil, com uma taxa de 13,1\% (abril de 2018) são atingidas 13,7 milhões de pessoas (com aumento estimado em 600 mil pessoas nos sete meses anteriores) (G1, [2018]).

2 Segundo relatório do Banco Mundial sobre o Brasil, "outra alternativa seria, em vez de cortar seus gastos, o governo brasileiro deveria aumentar suas receitas tributárias e reduzir os altos pagamentos de juros sobre sua dívida pública. Certamente, há escopo para aumentar a tributação dos grupos de alta renda [...] e reduzir a dependência dos tributos indiretos, que sobrecarregam os mais pobres" (BANCO MUNDIAL, 2017, p. 8). A explicitação dessas medidas, entretanto, cumpre muito mais um papel de atribuir ao documento uma suposta imparcialidade técnica, já que elas são nitidamente secundarizadas quando se afirma: "No entanto, essas medidas adicionais não substituem o combate às causas fundamentais do aumento dos gastos públicos e a revisão das excessivas responsabilidades/obrigações associadas ao Estado brasileiro" sem as quais "o Brasil inevitavelmente passará por outras crises fiscais e terá de implementar outros ajustes dolorosos no futuro" (ibid., p. 8).

${ }^{3}$ Ver, por exemplo, https://exame.abril.com.br/brasil/a-filantropia-como-negocio/.

${ }^{4}$ Segundo Roberto Leher, reitor da UFRJ e estudioso do assunto, "Apenas uma organização, Kroton-Anhanguera, possui mais estudantes do que todas as 63 universidades federais reunidas!” (LEHER, 2017), incluindo-se a ampliação da educação à distância.

${ }^{5}$ A seguinte passagem em Lukács (2012) expressa essa organicidade dialética entre essência e historicidade: "A ontologia geral ou, em termos mais concretos, a ontologia da natureza inorgânica como fundamento de todo existente é geral pela seguinte razão: porque não pode haver qualquer existente que não esteja de algum modo ontologicamente fundado na natureza inorgânica. Na vida aparecem novas categorias, mas estas podem operar com eficácia ontológica somente sobre a base das categorias gerais, em interação com elas. E as novas categorias do ser social relacionam-se do mesmo modo com as categorias da natureza orgânica e inorgânica. [...] A indagação acerca da especificidade do ser social contém a confirmação da unidade geral de todo ser e simultaneamente o afloramento de suas próprias determinações específicas" (LUKÁCS, 2012, p. 27)

${ }^{6}$ Cumpre destacar, evitando-se uma oposição mecânica, que humanização está sempre articulada dialeticamente com alienação, uma vez que a superação da alienação (embora se possam admitir saltos) não é um momento, um instante de iluminação, mas só pode decorrer de um longo e contínuo processo (DUARTE, 2013).

7 A esse respeito, ver, em especial, Saviani (2008, 2005).

${ }^{8}$ A esse respeito, Cf. Bonfim (2015), Netto (2004), Santos (2007) e Silveira Junior (2016).

${ }^{9}$ Essas diretrizes postulam uma formação profissional ancorada nos valores e princípios do Código de Ética do Assistente Social e articulam as competências e habilidade profissionais às dimensões teórico-metodológicas, ético-políticas e técnico-operativas da profissão em uma perspectiva de totalidade.

${ }^{10} \mathrm{O}$ conjunto CFESS/CRESS no documento "Subsídios para a Atuação de Assistentes Sociais na Política de Educação" ([201?], p. 7) discute a concepção de trabalho profissional na educação ao afirmar que: "O intuito maior é comunicar a categoria profissional com elementos constituídos a partir de uma concepção de educação coerente com o nosso projeto ético-político profissional, que, por sua vez, reconheça as particularidades da atuação do/a assistente social na referida política pública e, diante do contexto político e ideológico de ofensivas capitalistas, contribua para a intensificação da luta pela educação como direito social, como prática emancipatória, e para a consolidação do Serviço Social na educação."

${ }^{11}$ O estudo de Marro (2011, p. 320) discute a relação do Serviço Social com os movimentos e lutas das classes subalternas, por considerar a importância que essa relação teve no processo de redimensionamento crítico do Serviço Social brasileiro, através das experiências de extensão universitária e estágio supervisionado. Para a autora: "o trabalho profissional articulado aos movimentos sociais deve assumir o desafio da incorporação, na nossa formação universitária e nos diversos âmbitos de atuação profissional, das demandas e reivindicações das classes subalternas nos seus processos de organização, significando a possibilidade de criação de novos espaços de intervenção. 
Assinalamos que essas estratégias constituem uma possibilidade real de criação de novas bases de legitimidade da profissão junto aos grupos subalternos, afirmando outras relações pedagógicas (ABREU, 2002) com os movimentos sociais que possam reforçar sua autoorganização. O compromisso da categoria com as lutas sociais e com a mobilização popular significa um momento importante do processo de concretização dos princípios apontados no projeto ético-político, possibilitando, inclusive, a potenciação e qualificação da própria organização política da mesma".

${ }^{12}$ A esse respeito, ver Abreu (2002).

${ }^{13}$ Sindicato Nacional dos Docentes de Ensino Superior.

${ }^{14} \mathrm{O}$ anteprojeto de Lei Federal "Programa Escola sem Partido", propôs que este Programa deveria ser aplicável aos sistemas de ensino da União, dos Estados, do Distrito Federal e dos Municípios. Em seu Art. 2‥ O programa propõe que "A educação nacional deverá atender aos seguintes princípios: dignidade da pessoa humana; neutralidade política, ideológica e religiosa do Estado; pluralismo de ideias e de concepções pedagógicas; liberdade de aprender, ensinar, pesquisar e divulgar o pensamento, a arte e o saber; liberdade de consciência e de crença; proteção integral da criança e do adolescente; direito do estudante de ser informado sobre os próprios direitos, visando ao exercício da cidadania; direito dos pais sobre a educação religiosa e moral dos seus filhos, assegurado pela Convenção Americana sobre Direitos Humanos". O Programa tem clara opção pela neutralidade teórica e política na formação de discentes em todo o país, com claros vetos às discussões sobre sexualidade, gênero, religião, política partidária, manifestações políticas. Propõe, ainda o controle sobre os conteúdos curriculares ministrados nos espaços educacionais.

${ }^{15}$ Segundo Marques e Mendes (2013, p. 191): “Nas últimas décadas, a incapacidade demonstrada pelo capital em recuperar as condições de sua lucratividade, em um quadro de exacerbação crescente do capital fictício e de sua mundialização, tem resultado no aumento da competitividade no plano internacional e, em decorrência disso, na deterioração das condições de trabalho dos trabalhadores nas economias centrais e na pressão pelo rebaixamento do nível de cobertura da proteção social no mundo inteiro, em particular da aposentadoria".

Recebido em: 18/7/2018

Aprovado em: 9/4/2019.

Publicado em: 10/10/2019.

Correspondência para:

Joana Valente Santana

Universidade Federal do Pará

Instituto de Ciências Sociais Aplicadas

Faculdade de Serviço Social

Rua Augusto Corrêa, 01 - Guamá

66075-900, Belém, PA, Brasil

\section{Autores:}

JoANA VALENTE SANTANA

Doutora em Serviço Social pela Universidade Federal do Rio de Janeiro (UFRJ), Rio de Janeiro, RJ, Brasil. Professora no

Programa de Pós-graduação em Serviço Social (PPGSS/UFPA), Belém, PA, Brasil.

Orcid: https://orcid.org/0000-0003-4033-1317

E-mail: joanavalente@ufpa.br

BENEDITO de Jesus PINHEIRO FERREIRA

Doutor em Engenharia de Sistemas e Computação pela Universidade Federal do Rio de Janeiro (UFRJ), Rio de Janeiro, RS, Brasil.

Professor no Programa de Pós-graduação em Educação (PPGED/UFPA), Belém, PA, Brasil.

Orcid: https://orcid.org/0000-0003-1949-5077

E-mail: ferreira@ufpa.br

Endereço: Universidade Federal do Pará - Centro de Ciências Exatas e Naturais - Departamento de Informática

Rua Augusto Corrêa, 01 - Guamá - 66075-110, Belém, PA, Brasil 